\title{
MICROEMPREENDEDORISMO INDIVIDUAL (MEI) E SEUS EFEITOS SOBRE AS CONDIÇÕES SOCIAIS EM MUNICÍPIOS MINEIROS: UM ESTUDO EMPÍRICO
}

Mateus Cerqueira Anício Morais ${ }^{1}$

Magnus Luiz Emmendoerfer ${ }^{2}$

\footnotetext{
${ }^{1}$ Universidade Federal de Viçosa/ PPGADM/ Departamento de Administração e Contabilidade (DAD - UFV) e Universidade do Estado de Minas Gerais (UEMG) - Campus Carangola

${ }^{2}$ Universidade Federal de Viçosa/ PPGADM/ Departamento de Administração e Contabilidade (DAD - UFV)
} 


\section{MICROEMPREENDEDORISMO INDIVIDUAL (MEI) E SEUS EFEITOS SOBRE AS CONDIÇÕES SOCIAIS EM MUNICÍPIOS MINEIROS: UM ESTUDO EMPÍRICO}

Resumo: O objetivo deste trabalho é analisar o potencial efeito do Microempreendedorismo Individual (MEI) sobre as condições sociais de municípios, considerando suas possíveis reações sobre o emprego, renda e investimento público local em saúde e educação. Testou-se a hipótese de que o microempreendedorismo individual tende a afetar positivamente as condições sociais, haja vista os efeitos da formalização sobre o emprego, renda e a arrecadação tributária, registrados pela na literatura. Optou por utilizar um modelo de regressão linear com dados em painel como método de análise dos dados. Evidenciou-se um raso efeito da categoria de empreendedorismo estudada sobre as condições sociais no âmbito local e uma relação negativa entre tais variáveis. As evidências encontradas sustentam argumentos de que o microempreendedorismo individual pode estar relacionado ao redimensionamento de empresas e a trocas de relações trabalhistas, além de apresentar resultados próximos ao empreendedorismo motivado por necessidade.

Palavras-Chave: Microempreendedorismo Individual. Informalidade. Políticas Públicas. Condições Sociais.

\section{Introdução}

A informalidade é um fenômeno prejudicial ao desenvolvimento econômico dos países, seus efeitos têm sido amplamente estudados pela literatura acadêmica (BARGAIN; KWENDA, 2010; CORSEUIL; REIS; BRITO, 2015; DAU; CUERVO-CAZURRA, 2014;

KENYON; KAPAZ, 2005; PONCZEK; ULYSSEA, 2017). Os autores apontam para aspectos negativos dessa realidade, principalmente sobre as economias emergentes em função da perda de base tributária, da deslealdade concorrencial entre empresas, e da dificuldade de acesso ao crédito formal.

O Microempreendedorismo Individual (MEI) surge no Brasil como uma política de amenização desse contexto. Essa característica lhe é conferida pelos seus efeitos positivos sobre a formalização de negócios e inserção de novos empreendedores nos mercados, o que tende a afetar o emprego, a renda e a arrecadação tributária no âmbito municipal (CORSEUIL; NERI; ULYSSEA, 2014; SOUZA et al., 2016). A categoria MEI foi criada pela Lei Complementar n. ${ }^{\circ}$ 128/2008 que definiu o Microempreendedor Individual como aquele empreendedor autônomo, que possua o faturamento anual máximo de 60 mil reais e que tenha por limite empregatício apenas um colaborador em seu negócio.

Desde sua criação, essa modalidade vem crescendo no Brasil, totalizando 7.729.234 até Dezembro de 2017 (RELATÓRIOS ESTATÍSTICOS DO MEI, 2017). Esses números representam um avanço para o desestímulo à economia informal brasileira, que já abrangeu, segundo a Estimação do Tamanho da Economia Subterrânea no Brasil (2013), 16,8\% do Produto Interno Bruto (PIB) nacional, tendendo assim, a afetar o desenvolvimento econômico e a arrecadação tributária dos governos.
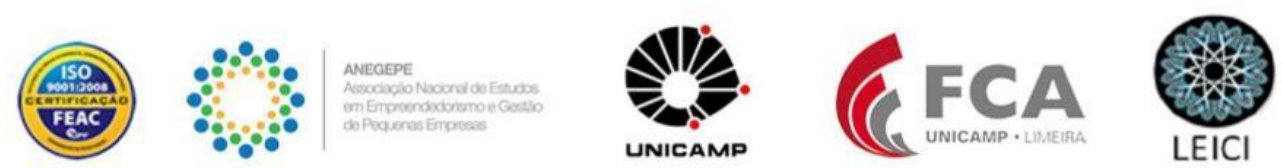
Muitos trabalhos acadêmicos registram as implicações da formalização sobre a receita dos governos e das condições socioeconômicas (FERREIRA, MARTINS, MOREIRA, 2012; MAGUEIRA, 2013; PAES, 2010; RIBEIRO, 2000), outros apontam para os benefícios do Programa de Microempreendedorismo Individual (MEI) para os indivíduos e para a administração pública (BEHLING; LENZI, 2010; JULIÃO, 2014; MARIA DE OLIVEIRA, 2012; VASCONCELOS, 2016), oferecendo base teórica e empírica para se levantar hipóteses a respeito dos efeitos do Microempreendedorismo Individual sobre as condições socioeconômicas no âmbito local, relação pouco evidenciada em pesquisas de periódicos científicos brasileiros.

O presente trabalho visa suprir essa lacuna de pesquisa tendo por objetivo analisar o potencial efeito do Microempreendedorismo Individual (MEI) sobre as condições sociais dos municípios, considerando suas possíveis reações sobre o emprego, renda e investimento público local em saúde e educação.

Enfatiza-se o âmbito municipal devido à natureza de baixo valor agregado das atividades exercidas pela maioria dos Microempreendedores Individuais (MEIs) (MOREIRA, 2013), o que pode implicar em baixos efeitos do microempreendedorismo sobre a condição social. Optou-se, portanto, por estudar esse fenômeno a partir dos municípios de Minas Gerais, unidade federativa com o maior número de municípios no Brasil e terceiro maior estado brasileiro em número de Microempreendedores Individuais (MEIs) (RELATÓRIOS ESTATÍSTICOS DO MEI, 2017).

Identificar a implicações da modalidade do Microempreendedorismo Individual sobre as condições sociais levanta questões sobre as medidas de estímulo à formalização de negócios irregulares para as economias locais. Ademais, essa pesquisa se insere em discussões a respeito de políticas públicas de estímulo ao empreendedorismo, trazendo à literatura acadêmica elementos sobre o empreendedorismo de baixo valor agregado, o que contribui para os debates sobre a importância de seu fomento pela administração pública (MORRIS et al., 2016; MORRIS; NEUMEYER; KURATKO, 2015; SHANE, 2009).

\section{Informalidade, Condições Sociais e Microempreendedorismo Individual (MEI)}

A informalidade é um fenômeno amplamente estudado na literatura acadêmica, as questões que a envolvem recebem atenção de diversos autores (BARGAIN; KWENDA, 2010; KENYON; KAPAZ, 2005; LEONTARIDI, 1998; PERRY et al., 2007). Esse fenômeno apresenta diferentes significados entre as pesquisas, no presente trabalho é entendida como um estado de não declaração formal da atividade econômica em exercício, tendo em vista o aparato legal dos países que as sediam (BEHLING; LENZI, 2010; KENYON; KAPAZ, 2005).

A economia informal chagou a movimentar grande parcela do mercado brasileiro, cerca de quarenta por cento (40\%) do PIB, segundo estudos de Mangueira (2013), que alerta para a magnitude dessa economia, ao compará-la com outros países latino-americanos, Argentina, México e Paraguai, Schneider (2005) aponta para uma proporção de $42 \%$ dos outputs da atividade econômica brasileira, provenientes de mercados subterrâneos para o período de 20022003.

As explicações para a grande amplitude informal na economia brasileira se dá, na visão de Kenyon e Kapaz (2005), principalmente pelos elevados impostos praticados no país.
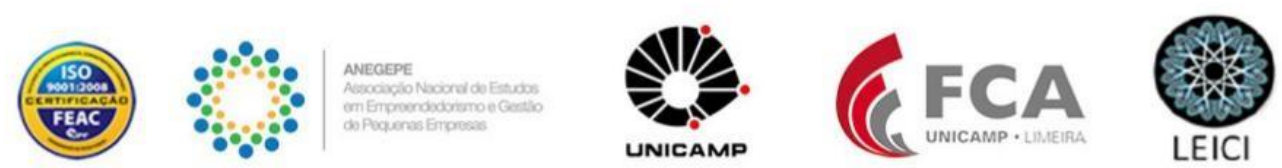
Com base nos resultados da survey "Doing Business" do Banco Mundial, de 2006, os autores destacam que as empresas brasileiras depreendem mais tempo para cumprir com suas obrigações físcais do que qualquer outra em países inclusos na pesquisa. Além do mais, as empresas brasileiras tendem a citar o peso dos impostos como um grande desestimulo ao seu funcionamento, de maneira mais frequente que empreendedores estabelecidos em outras nações.

A respeito dos impactos da economia informal sobre as condições sociais, existem posições divergentes entre alguns autores da área. Bargain e Kwenda (2010) demonstram, para o contexto de países emergentes (Brasil, México e África do Sul), que existem ganhos significativos para alguns grupos de indivíduos que permanecem no mercado informal, compensando os custos de não se formalizarem. Essa perspectiva é condizente com a persistência dos mercados informais entre as nações.

A maior parte dos autores, por sua vez, ressaltam os efeitos negativos da economia informal sobre as condições socioeconômicas dos países. Paes (2010) aponta para as implicações da informalidade sobre a queda da produtividade e do crescimento econômico, devido à perda de recursos de base tributária e, por conseguinte, redução da arrecadação e do investimento dos governos. Kenyon e Kapaz (2005) destacam que empreendimentos informais são menos produtivos e menos propensos a acessarem o capital financeiro, seus impactos negativos sobre realidades socioeconômicas são apresentados também por outros autores (FERREIRA; MARTINS; MOREIRA, 2012; RIBEIRO, 2000; PALMADE; ANAYIOTOS, 2005).

Políticas públicas de incentivo á formalização surgem, portanto, como um meio de auferir progressos no que se refere à promoção do emprego, renda e arrecadação tributária. Fajnzylber, Maloney e Montes-Rojas (2011) demonstram o efeito positivo de políticas de simplificação burocrática e de diminuição de impostos sobre a formalização, bem como, sobre o aprimoramento do desempenho das microempresas brasileiras. Kenyon e Kapaz (2005) destacam os pequenos avanços do Brasil nesse sentido, ainda naquela época.

Essa evidência apresenta resultados benéficos para as condições sociais, haja vista que trabalhadores relacionados à economia informal tendem a apresentar piores condições de vida, quando comparados àqueles registrados no mercado formal (CORSEUIL; REIS; BRITO, 2015). Barros, Mello e Pero (1993) apontam que indivíduos pertencentes à economia informal, possuem remuneração mais baixas, em relação aos trabalhadores formais, e por isso apresentavam maiores chances de habitarem em domicílios pobres e a viverem e situações de maior vulnerabilidade social.

Problematizações a respeito do mercado informal, bem como suas relações com o bemestar social, surgem na América Latina mais intensivamente a partir do Relatório do Programa Regional de Emprego para a América Latina e Caribe (PREALC) em 1978 (CORSEUIL; REIS; BRITO, 2015). O governo brasileiro, por sua vez, desde 1996, com a instituição do Sistema Integrado de Pagamento de Impostos e Contribuições das Microempresas e das Empresas de Pequeno Porte (Simples), tem realizado políticas públicas de estímulo à criação de empresas formais e formalização das já existentes, pela via da redução de encargos tributários e burocráticos (CORSEUIL; NERI; ULYSSEA, 2014).

Nesse sentido, em 2008 foi instituída pela Lei Complementar n. ${ }^{\circ}$ 128/2008 uma nova classificação de empreendedorismo, o Microempreendedor Individual, definido como aquele

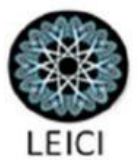


empreendedor autônomo, dotado de um faturamento anual máximo de 60 mil reais e que tenha por limite empregatício apenas um colaborador em seu negócio. Com essa nova medida, um novo padrão de contribuição tributária e de seguridade social foi estabelecido para empreendedores elegíveis a essa estratificação.

Os Microempreendedores Individuais (MEIs) tem um processo de obtenção de CNPJ simplificado e sem custos, estão isentos dos tributos federais (IR, PIS, Cofins, IPI e CSLLL) e contribuem com uma alíquota fixa de $5 \%$ sobre o salário mínimo para obterem acesso aos benefícios previdenciários. Tais medidas tendem a estimular significativamente a formalização das atividades empreendedoras elegíveis à essa classificação (CORSEUIL; NERI; ULYSSEA, 2014).

Os efeitos da política de Microempreendedorismo Individual (MEI) ainda estão sendo registrados na literatura. Corseuil, Neri e Ulyssea (2014) demonstram, a partir de uma análise exploratória, o êxito da política de microempreendedorismo individual brasileira no processo de fomento a essa modalidade e sobre a formalização de novos empreendimentos. Os autores alertam, entretanto, para a possibilidade de terceirização da mão de obra assalariada e da redução das escalas para microempreendimentos elegíveis.

Sobre esses aspectos, Maria de Oliveira (2012) salienta que existem indícios de que a política de Microempreendedorismo Individual (MEI) tem sido utilizada de maneira desvirtuada. Sugerindo que exista um rearranjo das relações trabalhistas, possivelmente ocorrendo a substituição do emprego pela prestação de serviços.

Não negligenciando esse possível contexto, trabalhos apontam uma série de benefícios da institucionalização do MEI como uma estratificação do empreendedorismo. Moreira (2013) ressalta os potenciais efeitos dessa política sobre a inclusão produtiva, a partir de uma análise de perfil do microempreendedor individual beneficiário do Programa Bolsa Família. A partir de um estudo de caso, Souza et al., (2016) destaca os efeitos positivos da política para o desenvolvimento local.

A partir do referencial teórico, o presente trabalho assume a hipótese de que o microempreendedorismo individual tende a afetar positivamente as condições sociais, haja vista os efeitos da formalização sobre as condições de emprego, renda e sobre a arrecadação tributária, como apontado pela teoria descrita.

Espera-se, por sua vez, um efeito baixo dessa variável explicativa, tendo por referência os achados de Fajnzylber, Maloney e Montes-Rojas (2011) e Assunção e Monteiro (2012), em análise sobre as medidas do Simples Nacional. Além disso, leva-se em consideração o caráter de baixo valor agregado para as atividades empreendedoras relacionadas ao Microempreendedorismo Individual (MOREIRA, 2013).

\section{Procedimentos Metodológicos}

O objetivo desse trabalho é analisar o potencial efeito do Microempreendedorismo Individual (MEI) sobre as condições sociais dos municípios, considerando suas possíveis reações sobre o emprego, renda e investimento público local em saúde e educação. Para isso optou por utilizar um modelo de regressão linear com dados em painel como método de análise dos dados. Entende-se que a utilização de dados em painel oferece uma série de vantagens frente a outros modelos estatísticos quando levado em conta a proposta dessa pesquisa.
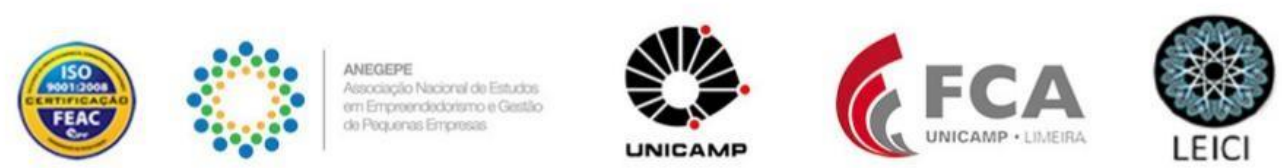
Um fator relevante na utilização desse método é a ampliação das observações a serem consideradas. Dados em painel são compostos por informações individuais variantes ao longo do tempo, além de providenciar maior número de informações e variabilidade dos dados, modelos em painel acarretam menor multicolinearidade, maior grau de liberdade e, consequentemente, maior confiabilidade, eficiência e robustez do modelo proposto (MARQUES, 2000; WOOLDRIDGE, 2010), justificando assim sua adequabilidade para se atender às expectativas teóricas da presente pesquisa.

Optou-se por utilizar dados secundários dos Municípios de Minas Gerais (853 municípios) no período de 2007 - 2013, devido à indisponibilidade de dados do IFDM para além desse ano. A escolha do estado de MG se justifica por ser o terceiro estado com maior número de MEIs, além de ser a UF com maior número de municípios do Brasil, sendo, portanto, um caso propício para se entender a relação do Microempreendedorismo Inicial e as condições sociais a nível municipal.

Buscou-se estimar um modelo de regressão múltipla, tendo o Índice FIRJAN de Desenvolvimento Municipal (IFDM) como variável dependente. Esse índice, já utilizado por outras pesquisas para referenciar as condições sociais dos municípios no Brasil, acompanha anualmente o desenvolvimento socioeconômico brasileiro levando em consideração estatísticas públicas oficiais de emprego, renda, saúde e educação.

Os resultados do IFDM variam em uma escada de 0 a 1 , oferecendo uma classificação das condições sociais dos municípios brasileiros. Pela metodologia de apuração do índice, considera-se um município com baixo desenvolvimento aquele que possui o IFDM de 0 à 0,4 , médio desenvolvimento aquele que se situa entre 0,4 e 0,6 , alto aquele com o índice de 0,6 à 0,8 e muito alto desenvolvimento aquele que se posiciona acima de 0,8.

O modelo em painel desenvolvido nesse artigo pode ser descrito, em sua forma básica pela Expressão 1.

Em que:

IFDM it: proxy de condições sociais para cada um dos i estados para o ano t;

$\alpha_{1:}$ Constante do modelo para cada município i;

$\delta$ : é o coeficiente angular da variável defasada a ser estimada;

IFDM $M_{i t-n:}$ proxy de condições sociais defasada para cada um dos i municípios para

o ano $\mathrm{t}-1$;

B: coeficiente angular de cada variável a ser estimada;

$X_{i t:}$ representante das variáveis explicativas para cada município i e para o ano t;

$u_{i t}$ : termo de erro do modelo

As variáveis representadas no modelo estão descritas no Quadro 1.

Quadro 1: Descrição de variáveis e fonte dos dados da pesquisa.

$\begin{array}{llll}\text { Variável Descrição } & \text { Fonte } & \text { Expectativa }\end{array}$




\begin{tabular}{|c|c|c|c|c|}
\hline XI & EPE & \multicolumn{2}{|c|}{$\begin{array}{l}\text { Encontro de Estudos sobre Empreendedorismo } \\
\text { e Gestão de Pequenas Empresas }\end{array}$} & $\begin{array}{r}\text { São Paulo/SP } \\
04 \text { a } 06 \text { de julho de } \\
2018\end{array}$ \\
\hline Ifdm & $\begin{array}{l}\text { Índice I } \\
\text { (IFDM), } \\
1 .\end{array}$ & $\begin{array}{l}\text { N de Desenvolvimento Municipal } \\
y \text { de condições sociais, variação de } 0 \text { a }\end{array}$ & FIRJAN & $\begin{array}{c}+ \\
\text { (defasagem) }\end{array}$ \\
\hline
\end{tabular}


Pib

nmei

psfpcpt

aprov

Iptu

Itbi

Issqn

tipcs

trtag

Energ

estab50

alpt

Esgoto
Produto Interno Bruto per capita municipal (mil) em logaritmo natural (ln).

Número acumulado de Microempreendedores Individuais (MEIs) por município.

Número de pessoas totais atendidas pelo Programa de Saúde da Família (PSF) sobre a população estimada.

Razão do número de alunos aprovados no ensino fundamental no ano vigente pelo número total de alunos matriculados no ensino fundamental multiplicado por 100 .

Arrecadação anual de Imposto Predial e Territorial Urbano (IPTU) per capita em logaritmo natural.

Arrecadação anual de Imposto de Transmissão de Bens Imóveis (ITBI) per capita em logaritmo natural.

Arrecadação anual de Imposto Sobre Serviços de Qualquer Natureza (ISSQN) per capita em logaritmo natural.

Número de famílias atendidas pela Estratégia de Saúde da Família cuja moradia consiste em alvenaria, divido pelo cadastro de famílias no psf.

Número de famílias atendidas pela Estratégia de Saúde da Família cujo tratamento de água é dado pela filtragem da água recebida, divido pelo cadastro familiar no psf.

Número de famílias atendidas pela Estratégia de Saúde da Família que são atendidas com serviço de energia elétrica, divido pelo cadastro familiar no psf.

Total de estabelecimentos que empregam acima de 50 trabalhadores.

Razão do número de alunos matriculados no ensino fundamental pelo número de turmas disponíveis para o ensino fundamental multiplicado por 100.

Número de famílias atendidas pela Estratégia de Saúde da Família atendida com serviço público de coleta seletiva, divido pelo cadastro familiar no psf.

Número de famílias atendidas pela Estratégia de Saúde da Família atendida com serviço de esgoto para captação de fezes e urina, divido pelo cadastro

\section{IBGE}

Portal do

Empreendedor

DATASUS/SUS e FINBRA

\section{EDUCACENSO/I}

NEP/MEC

FINBRA

FINBRA

FINBRA

DATASUS/SUS

DATASUS/SUS

$+$

DATASUS/SUS

RAIS/CAGED TEM

EDUCACENSO/I NEP/MEC

DATASUS/SUS

DATASUS/SUS

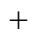
$+$ 
familiar no psf.

Fonte: Elaborado pelos autores

Entende-se, no modelo construído nesse trabalho, que o histórico das condições sociais é relevante para explicar as condições do presente. Nesse sentido optou-se por incluir uma defasagem de dois (2) anos para o Índice FIRJAN de Desenvolvimento Municipal (IFDM) presente no modelo.

Há, portanto, o estabelecimento de um painel dinâmico, que pode ser caracterizado pela: (i) inclusão de valores passados da variável dependente para explicar ela mesma; (ii) pela heterogeneidade entre a variável dependente e variável (eis) independentes e/ou (iii) quando ocorre a heterogeneidade não observada, pelo efeito individual que varia ao longo do tempo (CAMERON; TRIVERDI, 2009).

Considera-se, portanto, a endogeneidade existente no próprio caráter dinâmico do modelo, expressado pela defasagem do IFDM como variável explicativa. Há endogeneidade também, pela composição metodológica do próprio índice, na inclusão de variáveis diretas de condições sociais (psfpcpt, aprov, tipcs, trtag, energ, alpt, lixocol e esgoto) e na inclusão do total de estabelecimentos que empregam acima de cinquenta trabalhadores (estab50).

O modelo é estimado pelo Método dos Momentos Generalizados (GMM) que, nesse trabalho, se dá por "System GMM", tendo em vista a superioridade no número de indivíduos (853 municípios mineiros) frente um período de tempo de sete (7) anos em analise. O "System GMM", desenvolvido por Arellano-Bond (1991) e Arellano-Bover (1995), tem como hipótese a não correlação entre o instrumento de primeira diferença com o efeito fixo, o que aumenta o número de instrumentos e sua eficiência.

Para testar a validação dos instrumentos, Arellano e Bond (1991) sugere a utilização do Teste Sargan, bem como o teste Arellano-Bond para se testar autocorrelação serial dos erros em primeira e segunda diferença. Espera-se que os erros sejam correlacionados em primeira ordem e não autocorrelacionados em segunda ordem para garantir a robustez do modelo estimado.

\section{Resultados}

Tendo realizado os procedimentos metodológicos previamente descritos, foi possível obter resultados que demonstram a relação existente entre o as condições sociais e o microempreendedorismo individual. Ressalta-se que, além do número de MEIs, foi necessária a inclusão de um conjunto de variáveis de controle com potencial poder explicativo para as condições sociais.

Nesse sentido é possível extrapolar o elemento central de análise, levando em consideração os efeitos encontrados para todos os fatores inclusos na regressão estimada. A Tabela 1 apresenta a descrição das estatísticas das variáveis presentes no modelo.

Tabela 1. Estatísticas Descritivas

\begin{tabular}{cccccc}
\hline Variáveis & Obs & Média & Desv. Padrão & Min & Max \\
\hline Ifdm & 5.864 & 0,631 & 0,094 & 0,287 & 0,905 \\
Pib & 5.864 & 2,238 & 0,620 & 0,888 & 5,831 \\
\hline
\end{tabular}




\begin{tabular}{cccccc}
\hline Nmei & 4.170 & 196,028 & 1547,383 & 1 & 71289 \\
Psfpcpt & 5.783 & 0,910 & 0,362 & 0 & 6,738 \\
Aprov & 5.857 & 88,941 & 5,779 & 62 & 100 \\
Iptu & 5.864 & 1,922 & 1,518 & $-13,246$ & 7,049 \\
Itbi & 5.864 & 2,060 & 1,230 & $-6,605$ & 6,269 \\
Issqn & 5.864 & 3,418 & 1,072 & $-6,748$ & 8,748 \\
TipCs & 5.783 & 0,813 & 0,194 & 0 & 1,285 \\
Trtag & 5.783 & 0,937 & 0,111 & 0,001 & 1,637 \\
Energ & 5.783 & 3,069 & 0,916 & 0,004 & 9,157 \\
estab50 & 5.704 & 12,470 & 91,765 & 0 & 2725 \\
Alpt & 5.857 & 21,402 & 3,157 & 9,3 & 32.8 \\
Lixocol & 5.783 & 2699,866 & 1591,462 & 1 & 5425 \\
Esgoto & 5.783 & 2623,714 & 1442,695 & 1 & 4789 \\
\hline
\end{tabular}

Fonte: Elaborado pelos autores

As estatísticas descritivas reforçam as considerações sobre as desigualdades regionais historicamente existentes no estado de Minas Gerais, já destacadas por alguns autores (CARVALHO FILHO, 2006; DOMINGUES; MAGALHÃES; FARIA, 2009; FERREIRA JÚNIOR et al., 2017; SCAVAZZA, 2002). Os municípios mineiros possuem, em média, um IFDM de 0, 631, esse índice aponta para uma média alta em termos de desenvolvimento socioeconômico para o estado.

A variação individual entre os municípios ao longo do tempo, por sua vez, retrata a discrepância regional em termos de desenvolvimento socioeconômico. Existem, no estado mineiro, realidades municipais que variam desde um nível mais baixo de desenvolvimento registrado pelo índice, como pode ser observado pelo valor mínimo de 0,287 na tabela 1 , até um nível "muito alto" de desenvolvimento, como classifica a metodologia do índice para valores acima de 0,8, o IFDM máximo registrado no banco de dados dessa pesquisa é de 0,905.

Essa realidade é reforçada pelos valores máximos e mínimos das variáveis explicativas diretamente relacionadas às condições sociais de saúde. Este é o caso dos fatores que medem as condições de moradia das famílias atendidas pela Estratégia de Saúde da Família (tipcs), antigo Programa Saúde da Família (PSF), as condições de acesso à água filtrada (trags), à energia elétrica (energ), à coleta de lixo (lixocol) e ao tratamento de esgoto (esgoto). Variáveis essas que demonstram a precariedade na condição de vida de algumas famílias nos municípios estudados.

A arrecadação tributária dos municípios, representado no modelo pelas variáveis "iptu", "itbi" e "issqn", também apresentam uma extensão consideráveis para seus limites máximos e mínimos. Esse contexto pode estar relacionado com a grande quantidade de municípios de pequeno porte no estado de Minas Gerais (IBGE, 2016). Justifica-se os valores arrecadatórios negativos devido à sua apresentação em logaritmo natural, que assume esses resultados para valores de " $x$ " menores que 1 (um).

Os estabelecimentos que empregam mais de cinquenta funcionários (estab50) estão, em sua maioria, concentrados na capital mineira, Belo Horizonte, que abarcava 2725 empreendimentos dessa categoria em 2013. Em contrapartida, cerca de cinco municípios não 
sediaram estabelecimentos desse porte em pelo menos um dos anos no período em análise, são eles Pocrane, Mathias Lobato, Itambé do Mato Dentro, Fronteira dos Vales e Ponto Chique.

Além disso, o município de Belo Horizonte contém a maior parte dos Microempreendedores Individuais (MEIs) do estado de Minas Gerais, 71.289 para o ano de 2013, o valor máximo apontado na tebela 1. A quantidade de MEIs presentes na capital mineira excede substancialmente o número de empreendedores dessa categoria em outros municípios no mesmo ano. A segunda maior cidade em Microempreendedorismo Individual para o mesmo ano é Contagem, com 17.171 MEIs, seguida por Uberlândia, o terceiro município com maior número de MEIs para 2013, 16.158.

Esse contexto aponta para uma maior interferência dos dados provenientes do município de Belo Horizonte sobre o modelo estimado nessa pesquisa, em especial no que se refere à variável central de análise, quando comparados seus patamares frente a realidades das outras unidades federativas. Optou-se por manter os dados provenientes da capital mineira sob a expectativa de contribuição da mesma para um efeito significativo da variável em análise em uma perspectiva agregada. Na tabela 2 estão apresentados os resultados do modelo estimado. Tabela 2. Fatores explicativos das condições sociais em municípios mineiros.

\begin{tabular}{|c|c|c|}
\hline Variáveis & IFDM & Std. Err. \\
\hline L1. & $0,538 * * *$ & $(0,036)$ \\
\hline L2. & $0,152 * * *$ & $(0,028)$ \\
\hline Iptu & 0,004 & $(0,003)$ \\
\hline L1. & 0,005 & $(0,003)$ \\
\hline L2. & 0,001 & $(0,002)$ \\
\hline Itbi & $-0,006^{*}$ & $(0,003)$ \\
\hline L1. & $-0,001$ & $(0,004)$ \\
\hline L2. & 0,001 & $(0,002)$ \\
\hline Issqn & $-0,008^{*}$ & $(0,004)$ \\
\hline L1. & 0,002 & $(0,004)$ \\
\hline L2. & $-0,002$ & $(0,003)$ \\
\hline Nmei & $-5,56 \mathrm{e}-07 *$ & $(3,02 \mathrm{e}-07)$ \\
\hline L1. & $-5,67 e-07$ & $(7,89 \mathrm{e}-07)$ \\
\hline PIB & 0,012 & $(0,011)$ \\
\hline L1. & 0,003 & $(0,011)$ \\
\hline L2. & 0,009 & $(0,008)$ \\
\hline Psfpcpt & 0,012 & $(0,009)$ \\
\hline Aprov & $0,002 * * *$ & $(0,001)$ \\
\hline TipCs & $0,036^{* *}$ & $(0,016)$ \\
\hline Trtag & $0,032 * *$ & $(0,016)$ \\
\hline Energ & 0,001 & $(0,002)$ \\
\hline Estab50 & 0,000 & $(0,000)$ \\
\hline Alpt & $0,003 * *$ & $(0,001)$ \\
\hline Lixocol & $-4,43 e-07$ & $(1,88 \mathrm{e}-06)$ \\
\hline Esgoto & $-1,57 \mathrm{e}-07$ & $(1,28 \mathrm{e}-06)$ \\
\hline
\end{tabular}




\begin{tabular}{|c|c|c|}
\hline _cons & $-0,123$ & $(0,079)$ \\
\hline $\mathrm{N}^{\mathrm{o}}$ de Observações & 3.101 & \\
\hline Prob>Chi2 & $0,000 * * *$ & \\
\hline Sargan ( $p$-valor) & $0,0198 * * *$ & \\
\hline Arellano-Bond (z-calc) & $\begin{array}{l}1^{\circ}[0,000 * * * \\
2^{\circ}[0,0972\end{array}$ & \\
\hline
\end{tabular}

Fonte: Elaborado pelos autores. Nota: (***) nível de significância à 1\%, (**) nível de significância à 5\%. (*) nível de significância à 10\%. Estimativas com erros padrões robustos. Erro padrão correspondente entre parênteses.

Foram ao todo 3.101 observações inclusas no modelo que, por sua vez, se mostrou válido em todos os seus parâmetros, como pode ser evidenciado pelo valor significativo resultante do teste em Chi2, a um nível de confiança de $99 \%$.

Os instrumentos utilizados na estimação do modelo foram validados pelo teste Sargan para $1 \%$ de significância. Além disso, também a um nível de $1 \%$ de significância, é possível identificar autocorrelação serial em primeira ordem no modelo e ausência da mesma para os erros em segunda diferença, como recomendado para validação pela teoria (ARELLANO, MANUEL; BOND, 1991).

\section{$5 \quad$ Análise e Discussão}

Em sua maioria, as variáveis explicativas inclusas no modelo possuem baixo potencial de influência sobre as condições sociais, quando consideradas de maneira individualizada. Esse contexto está relacionado ao caráter multidimensional dos aspectos determinantes do desenvolvimento humano, que por sua vez, possui um conjunto variado de determinantes que dificilmente explicam de maneira particular as variações sociais e econômicas a maiores amplitudes (OTRONELI; MARIANO, 2014).

Em contrapartida, o histórico das condições sociais é o fator dotado de maior potencial de influência sobre as condições socioeconômicas correntes nos municípios estudados. Esse contexto pode ser evidenciado pelos valores significativos das defasagens do Índice FIRJAN de Desenvolvimento Municipal (IFDM), que afeta positivamente a variável explicada no modelo. Além disso, os resultados encontrados apontam, com 99\% de confiança, que os valores defasados do IFDM tendem a exercerem menores influências sobre as condições sociais correntes com o passar do tempo.

Esse resultado é condizente com evidências da literatura a respeito da trajetória dependente (path dependence) do desenvolvimento socioeconômico, que argumenta sobre uma realidade incremental dos avanços nas condições sociais e econômicas das cidades, estados e países (BERNARDI, 1976; CERQUEIRA, 2016). Tal perspectiva, por sua vez, leva em consideração elementos institucionais (formais e informais), não contemplados nessa pesquisa. Estão incluídas nessa vertente, variáveis relacionadas aos aspectos legislativos, bem como aos fatores culturais existentes em uma sociedade (CAMPBELL, 2010; PAUL PIERSON, 2004).

Tem-se, também, por resultado dessa pesquisa o efeito significativo das variáveis relacionadas à arrecadação tributária, ITBI e ISSQN. Espera-se, teoricamente, uma ação positiva da receita tributária sobre as condições sociais, haja vista a ampliação das 
possibilidades de investimentos pela administração pública local (MARIA DE OLIVEIRA, 2012; SCAVAZZA; GERAIS, 2002). Foi evidenciado, contudo, um efeito significativo negativo das variáveis explicativas em questão.

Tal resultado torna-se aceitável a uma significância de 10\%, ele demonstra, como já mencionado, o baixo potencial de explicativo das variáveis ITBI e ISSQN para as diferentes condições sociais, bem como o efeito negativo dessas variáveis correntes sobre o IFDM. Uma possível justificativa para essa relação seria o curto espaço de tempo para o investimento público após a receita proveniente da arrecadação desses tributos, as mudanças nas condições sociais, portanto, não seria afetada positivamente no curto período de tempo analisado.

Em contrapartida, a arrecadação presente tenderia a afetar o comportamento da atividade empreendedora nos mercados, implicando em menores frações de renda livre para compras e investimentos correntes. O efeito negativo da tributação sobre o empreendedorismo é registrado na literatura especializada (AUDRETSCH; GRILO; THURIK, 2007; LUNDSTRÖM; STEVENSON, 2006; VERHEUL et al., 2001), que aponta para seu efeito negativo sobre o emprego e a renda, elementos teoricamente intrínsecos à determinação das condições sociais.

Entre os fatores diretamente ligados às condições sociais consideradas pelo Índice FIRJAN de Desenvolvimento Municipal (IFDM), foram destacadas quatro variáveis significativas no modelo estimado. Tem-se que duas estão situadas no contexto das condições de saúde e outras duas sobre as condições de educação municipal.

Variáveis relacionadas à saúde se apresentaram mais significativas para explicar as condições sociais dos municípios mineiros, dentre elas estão as condições de moradia (tipcs) e o acesso à água filtrada (tratag), ambos referentes às famílias atendidas por políticas de Estratégia de Saúde da Família. Variáveis explicativas relacionadas ao âmbito escolar, percentual de aprovados no ensino fundamental (aprov) e número de alunos por turma (alpt), também se apresentam importantes no contexto estudado, entretanto, possuem menor potencial explicativo quando comparado aos fatores próximos a questões de saúde.

Finalmente, convém discutir os aspectos referentes ao objetivo central do presente trabalho, que visa estimar o possível efeito da política de Microempreendedorismo Individual (MEI) sobre as condições sociais, tendo por referência os municípios mineiros. A institucionalização da categoria "MEI" é recente e seus efeitos ainda são apresentados em caráter exploratório na literatura brasileira (CORSEUIL; NERI; ULYSSEA, 2014; MARIA DE OLIVEIRA, 2012; SOUZA et al., 2016).

Com base em trabalhos científicos previamente citados (FAJNZYLBER; MALONEY; MONTES-ROJAS, 2011; MALONEY, 2004; MONTEIRO, 2012), foi elaborada a hipótese de que o Microempreendedorismo Individual exerceria um efeito positivo sobre as condições sociais, tendo por premissa suas implicações benéficas sobre a formalização dos trabalhadores autônomos e para a inclusão de novos empreendedores no mercado. Esses resultados, por sua vez, tenderiam a ser pequenos, dado o caráter de baixo valor agregado das atividades relacionadas aos MEIs (MONTEIRO, 2012; MOREIRA, 2013).

A relação encontrada na presente pesquisa sustenta (a uma significância de 10\%) a hipótese referente aos rasos efeitos dessa categoria de empreendedorismo sobre as condições sociais no âmbito local. Ressalta-se, contudo, a natureza negativa do coeficiente dessa variável explicativa. Esse resultado contradiz as expectativas teóricas assumidas nesse

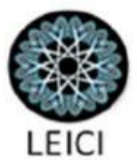


trabalho, algumas pesquisas, por sua vez, permitem que sejam levantados aspectos que justificam esse cenário (CORSEUIL; NERI; ULYSSEA, 2014; NAUDÉ, 2010).

Em uma análise exploratória do microempreendedorismo individual brasileiro Corseuil, Neri e Ulyssea, (2014) ressaltam três aspectos importantes a serem retomados nessa argumentação. Primeiramente têm-se o efeito da institucionalização da categoria MEI sobre a redução de escala de pequenos empreendimentos, resultante das transformações da matriz de trade off do proprietário do negócio, que passa a ver nessa nova estratificação um contexto favorável para a redução de seus custos, devido ao tratamento diferenciado em termos tributários, juntamente com os benefícios previdenciários que os acompanham (MARIA DE OLIVEIRA, 2012; SOUZA et al., 2016).

$\mathrm{O}$ redimensionamento da atividade empreendedora em pequenos estabelecimentos para a categoria do microempreendedorismo individual pode estar relacionado à diminuição no quadro de funcionários. Um elemento condizente com outra evidência desses autores, que apontam para a possibilidade de desassalariamento no mercado de trabalho, apontando indícios sobre as trocas de relações trabalhistas.

A política aumentou as chances de mudanças do estado empregatício, da condição de assalariado, para a prestação de serviços como Microempreendedor Individual (CORSEUIL; NERI; ULYSSEA, 2014; MARIA DE OLIVEIRA, 2012). Essa evidência apresenta um potencial efeito sobre as condições de emprego e renda na sociedade, elementos captados pela variável dependente em questão (IFDM).

No que tange aos aspectos tributários, os resultados sinalizaram para uma relação inversa entre a arrecadação municipal e as condições sociais. Nesse sentido, a redução da escala dos estabelecimentos não necessariamente implicam menores investimentos em saúde e educação por parte da administração pública local, elementos contemplados pelo IFDM. Esse efeito pode estar mais relacionado com receitas provenientes de transferência intergovernamentais.

Behling e Lenzi (2010), Corseuil et al. (2014) e Maria De Oliveira (2012) apontam para um potencial aumento da probabilidade de formalização de trabalhadores autônomos após a política do Microempreendedorismo Individual. Esse contexto somado às considerações de Naudé (2010), o qual indica que parte significativa dessa categoria opta pelo empreendedorismo como uma estratégia de sobrevivência, eferencem uma perspectiva de análise para os dados encontrados.

Esses argumentos aproximam o Micrempreendedorismo Individual (MEI) ao conceito de empreendedorismo por necessidade, o qual acorre devido à falta de outras opções ocupacionais (REYNOLDS et al., 1999). Sob essa perspectiva é possível interpretar o efeito negativo apresentado pelo numero de MEIs sobre as condições sociais dos municípios. A nova estratificação de empreendedorismo pode estar relacionada às taxas de desemprego existentes em cada localidade.

A literatura aponta para uma maior correlação do empreendedorismo por necessidade e baixas taxas de desenvolvimento econômico, sendo um fenômeno mais corriqueiro em economias emergentes (TAN, 2002; WONG et al., 2005). Essas evidências poderia explicar a relação negativa entre as condições sociais e o número de microempreendedores individuais presentes nos municípios. Tais argumentos carecem, por sua vez, de maiores sustentações teóricas, sendo, portanto, um elemento passível de futuras pesquisas.

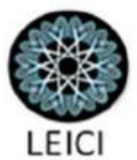




\section{Considerações Finais}

Buscou-se no presente trabalho analisar o efeito do Microempreendedorismo Individual (MEIs) sobre as condições sociais dos municípios mineiros. Essa proposta é sustentada por evidências teóricas a respeito dos significativos efeitos dos MEIs sobre a formalização de negócios que, antes, funcionavam em estado de irregularidade. A formalização tende a afetar os níveis de emprego, renda e a arrecadação tributária, aspectos considerados em mensurações das condições socioeconômicas de cidades, estados e países.

Os resultados apontaram para o baixo potencial de explicação do número de microempreendedores individuais sobre as condições sociais dos municípios mineiros. Esse cenário é condizente com as expectativas teóricas, devido ao tipo de atividade empreendedora exercida pelos indivíduos nessa categoria de ocupação, que em sua maioria, geram produtos e serviços de baixo valor agregado.

A natureza negativa do coeficiente do Microempreendedorismo Inicial, por sua vez, vai de encontro às expectativas iniciais desse trabalho. No cenário evidenciado para as unidades federativas estudadas, o MEI está relacionado com piores condições sociais para os municípios. Esse contexto ressalta as possibilidades de desvirtuamento das propostas do programa de Microempreendedorismo Individual, que potencialmente oferece condições de ganho para que micro e pequenos empresários reduzam suas escalas, o que estaria ligado a menores níveis de arrecadação, além da realocação das relações trabalhistas.

Essa pesquisa apresenta uma contribuição teórica, ao resgatar o conceito de empreendedorismo por necessidade a fim de construir um parecer explicativo dos efeitos negativos do MEI sobre as condições sociais. A maior quantidade de indivíduos levados a empreender para garantir sua subsistência, pode estar relacionada a contextos de concentração de renda, queda da produção e aumento do desemprego.

Nesse sentido, é possível apontar que um cenário crescente no número de empreendedores individuais na economia, nem sempre aponta indícios de melhores condições de vida para a população, como implicariam as premissas que levam em conta os feitos benéficos da formalização de empresas. Esse fenômeno, por sua vez, pode estar relacionado à falta de opções ocupacionais por parte da população economicamente ativa.

Tal argumento não desqualifica uma política de estímulo ao empreendedorismo por meio de desburocratização e simplificação tributária para o microempreendedor individual. A ausência da categoria MEI, para um cenário de empreendedorismo por oportunidade, poderia aumentar o número de indivíduos em situação de desemprego ou em atividades no mercado informal. Além disso, num contexto de elevados impostos, e subsequentes gargalos para a abertura e desenvolvimento de empreendimentos, ações nesse sentido apontam para um avanço do aparato legal brasileiro, no que se refere ao fomento da atividade empreendedora.

Ressalta-se como limitação dessa pesquisa a ausência de dados para um acompanhamento do caráter de longo prazo das mudanças nas condições sociais, o que acarretaria em melhores resultados de pesquisa. Indica-se para futuros estudos a apresentação de resultados robustos que aproximam a categoria MEI, dos motivos por se empreender por necessidade. Além disso, torna-se interessante pesquisar os efeitos dessa categoria empreendedora sobre o emprego, renda e arrecadação tributária, a fim de especificar os canais de influência desse fenômeno sobre as condições sociais para os municípios brasileiros.
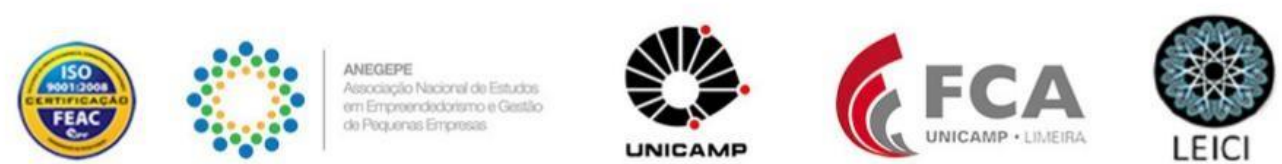


\section{Referências Bibliográficas}

ARELLANO, M; BOVER, O. Another Look at the Instrumental Variable Estimation of ErroComponents Model. Journal of Econometrics, v. 68, p. 29-51, 1995.

ARELLANO, Manuel; BOND, Stephen. The Review of Economic Studies, Ltd. Some Tests of Specification for Panel Data: Monte Carlo Evidence and an Application to Employment Equations Some Tests of Specification for Panel Data: Monte Carlo Evidence and an Application t o Employment Equations. Review of Economic Studies, v. 58, n. 58, p. 277-297, 1991.

AUDRETSCH, David B; GRILO, Isabel; THURIK, A Roy. Explaining entrepreneurship and the role of policy: A framework. Handbook of research on entrepreneurship policy, p. 1-17, 2007.

BARGAIN, Olivier; KWENDA, Prudence. Is Informality Bad? Evidence from Brazil, Mexico and South Africa. IZA Discussion Papers, n. 4711, p. 1-29, 2010.

BEHLING, Gustavo; LENZI, Fernando César. Você é mei? Porque? Uma análise dos influenciadores da decisão de formalização de microempreendedores individuais (mei). 2010, Passo Fundo: IX EGEPE, 2010. p. 1-15. Disponível em:

<http://www.egepe.org.br/2016/artigos-egepe/182.pdf>. Acesso em: 11 jun. 2017.

BE I, Bruno Boti. erspectivas evista de i ncias Sociais. Perspectivas: Revista de Ciências Sociais, v. 41, n. 0, 21 dez. 1976.

CAMPBELL, John L. Institutional Reproduction and Change. In: GLENN MORGAN, JOHN L. CAMPBELL, COLIN CROUCH, OVE KAJ PEDERSEN, AND RICHARD WHITLEY (Org.). . The Oxford Handbook of Comparative Institutional Analysis. [S.1.]: Oxford University Press, 2010.

CARVALHO, Francisco; FILHO, Duarte. Reflexões Sobre a Questão Regional Em Minas Gerais. , Cadernos BDMG., nº 13. Belo Horizonte: [s.n.], 2006.

CERQUEIRA, Kleber Chagas. Dependência da trajetória e mudança institucional nos processos de desenvolvimento. Revista Brasileira de Ciência Política, v. 19, n. 19, p. $253-$ $275,2016$.

CORSEUIL, Carlos Henrique; NERI, Marcelo Côrtes; ULYSSEA, Gabriel. Uma análise exploratória dos efeitos da política de formalização dos microempreendedores individuais. , Texto para Discussão., n ${ }^{\circ}$ 1939. Rio de Janeiro: [s.n.], 2014. Disponível em: <http://hdl.handle.net/10419/121626>. Acesso em: 11 jun. 2017.

CORSEUIL, Carlos Henrique; REIS, Mauricio Cortez; BRITO, Alessandra Scalioni. Critérios de classificação para ocupação informal: consequências para caracterização do setor informal e para a análise de bem-estar no Brasil. Estudos Econômicos, v. 45, n. 1, p. 5-31, 2015.

DAU, Luis Alfonso; CUERVO-CAZURRA, Alvaro. To formalize or not to formalize: Entrepreneurship and pro-market institutions. Journal of Business Venturing, v. 29, n. 5, p. 668-686, 2014. 
DOMINGUES, Edson Paulo; SOUZA MAGALHÃES, Aline; FARIA, Weslem Rodrigues. Infraestrutura, crescimento e desigualdade regional: uma projeção dos impactos dos investimentos do programa de aceleração do crescimento (PAC) em Minas Gerais. Pesquisa e Planejamento Econômico, v. 39, n. 1, p. 121-158, 2009.

FAJNZYLBER, Pablo; MALONEY, William F.; MONTES-ROJAS, Gabriel V. Does formality improve micro-firm performance? Evidence from the Brazilian SIMPLES program. Journal of Development Economics, v. 94, n. 2, p. 262-276, mar. 2011.

FERREIRA JÚNIOR, Sílvio et al. Desigualdades nas Necessidades em Saúde entre os Municípios de Minas Gerais: uma Abordagem Empírica no Auxílio às Políticas Públicas. Administração Pública e Gestão Social, v. 1, n. 2, p. 105-119, 28 abr. 2017.

IBGE. Estimativas da população dos municípios e unidades da federação brasileiros com data de referencia em $1^{\circ}$ de julho de 2016. . [S.1: s.n.]. Disponível em:

<ftp://ftp.ibge.gov.br/Estimativas_de_Populacao/Estimativas_2016/estimativa_dou_2016_20 160913.pdf>. Acesso em: 11 jul. 2017. , 2016

JULIÃO, Flávio. Fatores Determinantes da Satisfação de Usuários do Programa Microempreendedor Individual Determinants of the Satisfaction of the Brazilian Individual Micro-entrepreneur Program. TPA - Teoria e Prática em Administração, v. 4, n. 1, p. 156$179,2014$.

KENYON, Thomas; KAPAZ, Emerson. The Informality Trap: Tax Evasion, Finace, and Productivity in Brazil. , Public Policy for the Private Sector., n ${ }^{0}$ 301. [S.1: s.n.], 2005.

LUNDSTRÖM, A.; STEVENSON, L. A. Entrepreneurship policy: theory and practice. New York/Boston/Dordrecht/London/Moscow: Kluwer Academic Publishers, 2006.

MARIA DE OLIVEIRA, João. Empreendedor Individual: ampliação da base formal ou substituição do emprego? , Repositório do Conhecimento IPEA. [S.1: s.n.], 2012.

MOREIRA, RFC. Empreendedorismo e Inclusão Produtiva: uma análise de perfil do microempreendedor individual beneficiário do Programa Bolsa Família. Radar: tecnologia, produção e comércio exterior. [S.1: s.n.], 2013.

MORRIS, Michael H. et al. Distinguishing Types of Entrepreneurial Ventures: An IdentityBased Perspective. Journal of Small Business Management, v. 0, n. 0, p. 1-22, 2016.

MORRIS, Michael H.; NEUMEYER, Xaver; KURATKO, Donald F. A portfolio perspective on entrepreneurship and economic development. Small Business Economics, v. 45, n. 4, p. 713-728, 2015.

NAUDÉ, Wim. Entrepreneurship, developing countries, and development economics: new approaches and insights. Small Business Economics, v. 34, n. 1, p. 1-12, 7 jan. 2010.

OTTONELLI, J.; MARIANO, J. L. Pobreza multidimensional nos municípios da Região Nordeste. Revista de Administração Pública, v. 48(5), pp. 1253-1279, 2014.

PAUL PIERSON. POSITIVE FEEDBACK AND PATH DEPENDENCE. Politics in Time: History, Institutions, and Social Analysis. Princeton; Oxford: Princeton University Press, 2004. p. 17-53. 
SCAVAZZA, Juliana Franca; GERAIS, Minas. Diferenças socioeconômicas das regiões de minas gerais. . Belo Horizonte: [s.n.], 2002. Disponível em:

<https://www.almg.gov.br/export/sites/default/educacao/sobre_escola/banco_conhecimento/a rquivos/pdf/diferencas_socioeconomicas.pdf>. Acesso em: 11 jul. 2017.

SHANE, Scott. Why encouraging more people to become entrepreneurs is bad public policy. Small Business Economics, v. 33, n. 2, p. 141-149, 2009.

SOUZA, Donizeti Leandro De et al. Empreendedorismo e desenvolvimento local: uma análise do programa Microempreendedor Individual em Minas Gerais, Brasil.

Desenvolvimento em Questão, v. 14, n. 37, p. 262, 30 nov. 2016.

VASCONCELOS, KELLY SAMÁ LOPES DE. De empresário individual formal a microempreendedor individual (MEI): Uma análise dos benefícios da política de formalização. 2016. 1-64 f. Universidade Federal de Pernambuco, CAA, Programa de PósGraduação em Economia, 2016.

VERHEUL, Ingrid et al. An Eclectic Theory of Entrepreneurship. Erasmus, p. 48, 2001. Disponível em: <http://www.tinbergen.nl>. 